Johnson R. W. (1997) The impact of clearing Brigalow communities and consequences for conservation. In: Conservation Outside Nature Reserves (eds D. Lamb and P. Hale), pp. 359-363. Centre for Conservation Biology, University of Queensland, Brisbane, Qld.

McAlpine C. A., Fensham R. J. and Temple-Smith D. E. (2002) Biodiversity conservation and vegetation clearing in Queensland: Principles and thresholds. Rangeland Journal 24, 36-55.

Moore A. W., Russell J. S. and Coaldrake J. E. (1967) Dry matter and nutrient content of a subtropical semiarid forest of Acacia harpophylla F. Muell. (Brigalow). Australian Journal of Botany 15, 11-24.

Scanlan J. C. (1991) Woody overstorey and herbaceous understorey biomass in Brigalow (Acacia harpophylla) woodlands. Australian Journal of Ecology 16. $521-530$

Seabrook L., McAlpine C. and Fensham R. (2007) Spatial and temporal analysis of vegetation change in agricultural landscapes: A case study of two Brigalow (Acacia harpophylla) landscapes in Queensland, Australia. Agriculture Ecosystems and Environment 120, 211-228.

Webb A. A. (1984) Consequences of agricultural land use in the Brigalow Belt. In: The Brigalow Belt of Australia (ed. A. Bailey), pp. 131-147. Queensland Department of Primary Industries, Brisbane, Qld.

Weiner J. (1985) Size hierarchies in experimental populations of annual plants. Ecology 66, 743-752.

Young P. A. R., Wilson B. A., McCosker J. A., Fensham R. J., Morgan G. and Taylor P. M. (1999) Brigalow Belt. In: The Conservation Status of Queensland's Bioregional Ecosystems (eds P. S. Sattler and R. D. Williams), pp. 11/1-11/81. Environmental Protection Agency, Brisbane, Qld.

\subsection{0}

\section{A study of coarse woody debris volumes in two box-gum grassy woodland reserves in the Australian Capital Territory. Adrian D. Manning, ${ }^{1}$} David B. Lindenmayer and Ross B. Cunningham ( ${ }^{1}$ The Fenner School of Environment and Society, The Australian National University, Canberra, ACT 0200, Australia. Tel.: +61 2 6125 5415; Fax: 026125 0757; Email: adrian.manning@anu.edu.au; Centre for Resource and Environmental Studies, The Australian National University, Canberra, ACT 0200, Australia).

Key words: Blakely's Red Gum (Eucalyptus blakelyi), boxgum grassy woodlands, coarse woody debris, line intersect method, yellow box (Eucalyptus melliodora).

\section{Introduction}

Fallen timber or 'coarse woody debris' (CWD) has a major role in the structure and function of temperate forest ecosystems (Harmon et al. 1986). In particular, it is very important for biodiversity. In Australia, a gradual process of collection, stacking and burning (i.e. 'tidying') of CWD on farmland by landholders (Reid 1999), logging (Lindenmayer et al. 1999; MacNally et al. 2002) and firewood collection (Driscoll et al. 2000) has simplified habitats and removed CWD as a key structural element from landscapes. Removal of CWD is believed to have had major negative effects on Australian wildlife and volumes are probably much reduced in comparison to the recent pre-European past (e.g. MacNally et al. 2002). There is limited published data on CWD in Yellow Box-Red Gum Grassy Woodlands (Eucalyptus melliodora-E. blakelyi) - an endangered ecological community listed by the Australian Capital Territory (ACT) Government and (including White Box, Eucalyptus albens) by the New South Wales and Commonwealth Governments (ACT Government 2004; Department of the Environment and Heritage 2006).

Two key questions were investigated in this study: (i) where it occurs, what volumes of CWD are found in two Yellow Box-Blakely's Red Gum Grassy Woodlands in the north-east of the ACT; and (ii) what are the relationships between CWD volumes and woody vegetation cover? The overarching aim was to inform plans to augment CWD loads to improve ecological conditions in Yellow BoxBlakely's Red Gum Grassy Woodlands in the ACT.

\section{Study area and methods}

The study area was the north-east of the ACT. It comprises two adjacent nature reserves, Mulligan's Flat and Goorooyarroo, which together total approximately 1600 ha (ACT Government 2004). They contain the largest, most intact and contiguous Yellow Box-Blakely's Red Gum Grassy Woodlands in the ACT (ACT Government 2004). Grazing by domestic livestock and firewood collection stopped in Mulligan's Flat Nature Reserve when it was designated as a protected area in 1995. Goorooyarroo Nature Reserve was designated in 2004.

The pattern of existing vegetation cover and structure has been gathered from on-ground surveys by the reserve managers. These data have been used to divide the Mulligan's Flat and Goorooyarroo Nature Reserves into areas of generally homogenous vegetation cover (polygons) of between $<1$ ha and 90 ha for management purposes. Based on information in the database, polygons were separated into four categories: (i) Mulligan's Flat Nature Reserve - high tree cover; (ii) Mulligan's Flat Nature Reserve - low tree cover; (iii) Goorooyarroo Nature Reserve - high tree cover; (iv) Goorooyarroo Nature Reserve-low tree cover. Four polygons for surveying CWD were then chosen in each category, and within each polygon two sampling transects were established (32 transects total). Candidate polygons within each category were chosen to ensure they had sufficient representation of Yellow Box and Blakely's Red Gum.

A major challenge in highly modified box-gum grassy woodlands is the fact that most CWD has been removed, and that which is there has a highly variable distribution. This means that an unbiased, randomized sampling approach would yield very low densities. In this instance, this would not be very informative because a key overarching aim of this study was to inform a future experiment about plausible CWD loads. An inferential framework that was conditional on the presence of CWD was used. Therefore, in the field, two 100-m transects (see below) were selected in each polygon, and the criteria for selection of transects were (i) that they should be 'representative' of the CWD in the polygon where it does occur (i.e. one transect with high and one transect with low levels of CWD, although such distinct contrasts were not always possible); (ii) that the tree cover should reflect the cover class of the 
polygon; (iii) that the tree species mix along the transect should primarily consist of Yellow Box and Blakely's Red Gum; (iv) that CWD was 'natural' tree fall, and wood that had obviously been sawn (e.g. for past firewood collection), should be avoided if possible. Although this approach was deliberately biased, it did yield useful information about CWD loads and variability in those loads.

The line intersect method (Warren \& Olsen 1964; Van Wagner 1968) was used to estimate the volume of CWD per ha, and as the basis for tonnage calculations. This method relies on a single diameter measurement at the point of intersection, but has the assumptions that the log has no taper (i.e. is cylindrical) and that the intersection point is the mid-point (Waddell 2002).

The diameters of all logs greater than $10-\mathrm{cm}$ diameter were measured along each $100-\mathrm{m}$ transect. At the point of intersection, the diameter at a right angle to the central longitudinal axis was measured (Waddell 2002). Where the diameter at the point of intersection could not be measured directly (because the log was touching the ground), the nearest accessible point was measured if it had a similar diameter. If this was not possible, diameter was estimated by measuring half the diameter multiplied by two. Pieces of wood were tallied twice if the central longitudinal axis was intersected twice. This included forked trees and branches and trunks of the same tree. However, logs were not tallied if the central longitudinal axis ran along the line of intersection and was not crossed (Waddell 2002).

The following equation was used to calculated volume of CWD (Warren \& Olsen 1964; Van Wagner 1968):

$$
V=\frac{\pi^{2} \sum d^{2}}{8 L}
$$

where $d$, diameter $(\mathrm{cm})$ at right angles to the length of the $\log$ and $L$, length (m) of the transect and $V$, volume in cubic metres per hectare.
To calculate the tonnage of CWD in kilograms per hectare, the following formula (derived from Waddell 2002) was used: (cubic metres per hectare) $\times 1000 \mathrm{~kg} / \mathrm{m}^{3} \times$ specific gravity of wood.

Use of this formula has limitations. First, we were unable to identify the tree species of each piece of CWD and the specific gravity of each log. Therefore, we used a mean of the specific gravities for 'air-dry' timber based on published airdry densities for yellow box $\left(1075,1040\right.$ and $\left.1089.6 \mathrm{~kg} / \mathrm{m}^{3}\right)$ and Blakely's red gum $\left(1055 \mathrm{~kg} / \mathrm{m}^{3}\right)$ (Ilic et al. 2001); which was calculated as 1.0649 (i.e. $1064.9 \mathrm{~kg} / \mathrm{m}^{3}$ ). Air-dry density approximates to wood that has dried outside for a few years and is quite similar to greenwood density (J. Ilic, pers. comm.). Second, decay rates affect the specific gravity of wood (which is usually calculated for green wood) (Waddell 2002). In forests in the Pacific North-west of the USA, Waddell (2002) factored this into the above equation by multiplying by a 'decay class reduction factor' based on assigned decay classes and published figures. However, in this study, comprehensive figures for the decay status of the tree species of interest could not be found and meaningful decay classes were difficult to estimate in the field (see above). Therefore, the equation was not corrected for decay.

The survey design was fully balanced and factorial, and so a linear mixed model analysis (ANOvA) was used. Random effects were 'polygon' and 'transect' and fixed effects were 'reserve' and 'tree cover'. Estimated CWD volumes were log-transformed before analysis to meet underlying distributional and variance assumptions of our analysis.

\section{Results}

Estimated CWD volumes varied considerably from $3.0 \mathrm{~m}^{3} / \mathrm{ha}$ to $247.2 \mathrm{~m}^{3} / \mathrm{h}$ a with a mean value of $34.0 \mathrm{~m}^{3} / \mathrm{h}$ and a median value of $19.3 \mathrm{~m}^{3} / \mathrm{ha}$ (interquartile range $8.3-31.3 \mathrm{~m}^{3} / \mathrm{ha}$ ) (see Fig. 1). When volumes were converted, estimated CWD tonnages varied from 3.2 tonnes/ha to 263.2 tonnes/ ha with a mean of 36.2 tonnes/ha and a median of 20.5 (a)

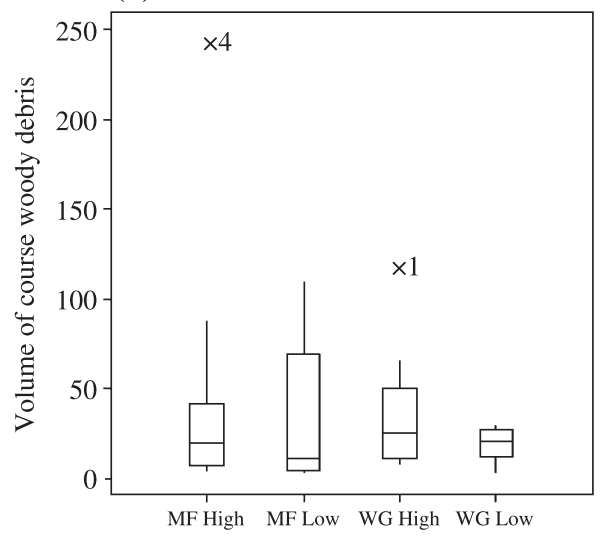

(b)

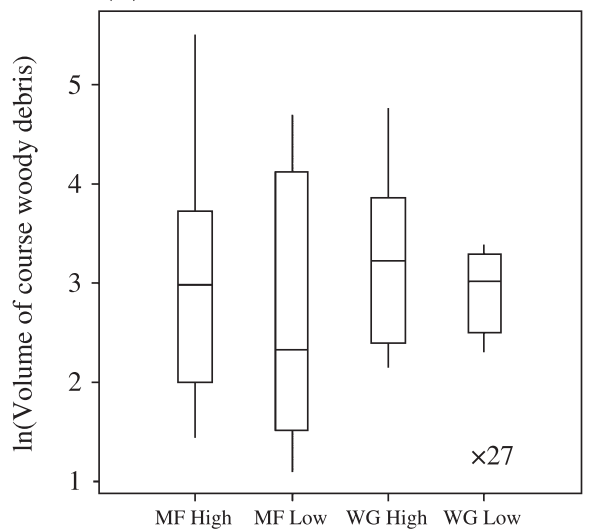

Figure 1. Box-plot showing volumes of CWD classified by tree cover class: (a) natural scale; (b) logarithmic scale. Mulligan's Flat Nature Reserves, MF; Goorooyarroo Nature Reserve, WG. 
Table 1. Mean of the logarithm of coarse woody debris volume cross classified by reserve and tree cover class. Back-transformed mean volumes $\left(\mathrm{m}^{3} / \mathrm{ha}\right)$ are given in brackets. Standard error of the difference of log volumes $=\mathbf{0 . 5 3 1}$

\begin{tabular}{lllll}
\hline & \multicolumn{2}{c}{ Tree cover class } & \multirow{2}{*}{ Difference } \\
\cline { 3 - 4 } & & \multicolumn{1}{c}{ High } & \multicolumn{1}{c}{ Low } & \\
\hline Reserve name & Mulligan's Flat & $2.86(17.5)$ & $2.72(15.1)$ & 0.14 \\
& Goorooyarroo & $3.24(25.5)$ & $2.79(16.3)$ & 0.45 \\
Difference & & 0.38 & 0.07 & \\
\hline
\end{tabular}

tonnes/ha (interquartile range 8.8-33.3 tonnes/ha). There was no evidence of a difference in the estimated volume of CWD between the two reserves, or the two tree cover classes and the interaction between reserve and tree cover class ( $P>0.30$ in all cases; see Table 1 for means). Random variation in the logarithm of CWD volumes between transects within polygons was high (1.358), but there was no evidence of additional random variation between polygons.

\section{Discussion and conclusions}

The range of CWD volumes was large, with a highly skewed distribution. Transects were selected to have at least one piece of wood of 10-cm diameter to be measured and were selected deliberately to contain examples of 'high' and 'low' CWD volume. Therefore, inferences are conditional on having CWD present. Although not ideal, this protocol was necessary to ensure meaningful results. Use of an unbiased sampling approach would have produced very low volume estimates because large parts of the reserve were observed to have no timber at all. Although interesting, in this context such results would not have been informative. Consequently, the estimated mean value presented here should be considered an upper estimate of the mean. However, because of the skewed distribution of the data, we consider the median and interquartile range more informative. Furthermore, the volume estimates should not be considered as absolute estimates of CWD in box-gum grassy woodlands per se, but rather estimates conditional on CWD being present. Based on these results, research into more refined methods for quantification of CWD in these types of woodland is now underway.

There was a trend suggesting that the higher tree cover class produced more CWD. However, this was not statistically significant. The lack of significance was unexpected because we had assumed that more trees would produce more CWD (Harmon et al. 1986). Stand basal area is widely considered to have a direct relationship with the amount of CWD produced (Grove 2001). The absence of this relationship may, in part, be explained by the history of reserve management before designation, and particularly the history of firewood collection. Results suggest that CWD may take a very long time to accumulate. This is supported by the lack of a significant difference between CWD loads in Mulligan's Flat and Goorooyarroo Nature Reserves despite the former being reserved since 1995 (and being protected from firewood collection) and the latter only in 2004.

This implies that CWD accumulation is very slow and reservation may not by itself, therefore, significantly arrest the declines of CWD-dependent species or processes, at least in the short to medium term.

The slow accumulation of CWD in the two reserves supports our plans for experimental CWD augmentation in the reserves. Other Australian research on the spatial distribution of CWD in woodlands suggests that augmentation should occur in a spatially heterogenous pattern. MacNally et al. (2001) argue that there are two approaches to CWD augmentation: (i) to restore CWD volumes to levels preceding European impact or; (ii) aim for targets based on effects on biodiversity. For example, MacNally et al. (2001) found that Yellow-footed Antechinus (Antechinus flavipes) occurred at a higher rate with CWD loads over 45 tonnes/ha. In addition, for birds, the same authors recommended high variance in CWD load (rather than an even load) (i.e. high spatial heterogeneity).

The high spatial variability of CWD found in this study suggests that CWD augmentation plans should try to maintain such variability, but increase overall volumes in targeted sites. An experiment to evaluate the effects of CWD augmentation on biodiversity is now underway in the reserves. Tonnages calculated in this study will help calibrate CWD volumes added in this experiment.

\section{Acknowledgements}

Thanks to Michelle Mabille for assistance in the field. Funding for this research was provided by the ACT Government. Thanks to Mark Dunford, Jugo Ilic, Peter Komidar, Sarah Sharp, Murray Evans, David Shorthouse, Nick Webb for providing information. Murray Evans, Joern Fischer and Nicki Webb kindly provided comments on earlier drafts. More information on the planned CWD augmentation experiment is available from Adrian Manning.

\section{References}

ACT Government (2004) Woodlands for Wildlife: ACT Lowland Woodland Conservation Strategy. Action Plan No. 27. Environment ACT, Canberra, ACT.

Department of the Environment and Heritage (2006) EPBC Policy Statement 3.5 - White Box-Yellow Box-Blakely's Red Gum Grassy Woodlands and Derived Native Grasslands Listing. Department of the Environment and Heritage, Canberra, ACT.

Driscoll D., Milkovits G. and Freudenberger D. (2000) Impact and Use of Firewood in Australia. CSIRO Sustainable Ecosystems, Canberra, ACT.

Grove S. J. (2001) Extent and composition of dead wood in Australian lowland tropical rainforest with different management histories. Forest Ecology and Management 154, 35-53.

Harmon M. E., Franklin J. F. et al. (1986) Ecology of coarse woody debris in temperate ecosystems. Advances in Ecological Research 15, 133-302.

llic J., Boland D., McDonald M., Downes G. and Blakemore P. (2001) Woody Density Phase 1 - State of Knowledge. National carbon accounting system. Technical report no. 18. The Australian Greenhouse Office, Canberra, ACT.

Lindenmayer D., Incoll R. D., Cunningham R. B. and Donnelly C. F. (1999) Attributes of logs on the floor of Australian Mountain Ash (Eucalyptus regnans) forests of different ages. Forest Ecology and Management 123. 195-203. 
MacNally R., Parkinson A., Horrocks G., Conole L. and Tzaros C. (2001) Relationships between terrestrial vertebrate diversity, abundance and availability of coarse woody debris on south-eastern Australian floodplains. Biological Conservation 99, 191-205.

MacNally R., Parkinson A., Horrocks G. and Young M. (2002) Current loads of coarse woody debris on south-eastern Australian floodplains: Evaluation of change and implications for restoration. Restoration Ecology 10 , $627-635$.

Reid J. R. W. (1999) Threatened and Declining Birds in the New South Wales Sheep-Wheat Belt. I. Diagnosis, Characteristics and Management. Consultancy report to NSW National Parks and Wildlife Service. CSIRO Wildlife and Ecology, Canberra, ACT.

Van Wagner C. E. (1968) The line intersect method in forest fuel sampling Forest Science 14, 20-26.

Waddell K. L. (2002) Sampling coarse woody debris for multiple attributes in extensive resource inventories. Ecological Indicators 1, 139-153.

Warren W. G. and Olsen P. F. (1964) A line intersect technique for assessing logging waste. Forest Science 10, 267-276.

\section{RIPARIAN \& STREAM ECOLOGY}

\subsection{5}

\section{Restoring ecological connectivity in the Margaret River: Western Australia's first rock-ramp fishways.}

Stephen J. Beatty, ${ }^{1}$ David L. Morgan ${ }^{1}$ and Antonietta Torre ${ }^{2}$ $\left({ }^{1}\right.$ Centre for Fish \& Fisheries Research, Murdoch University, South St Murdoch, WA 6150, Australia; Tel.: 61 0893602813; Fax: 61 0893606303; Email: s.beatty@murdoch.edu.au; ${ }^{2}$ Drainage and Waterways Branch Department of Water, Government of Western Australia Level 4, The Atrium, 168 St George's Terrace, Perth, WA 6000, Australia).

Key words: endemic fishes, galaxiids, Pouched Lamprey, spawning migration.

\section{Background}

Although a considerable amount of research has examined the impacts of barriers to fish migration elsewhere in Australia and the effectiveness of the many fishways constructed to overcome such barriers evaluated (e.g. Stuart \& Mallen-Cooper 1999; Barrett \& Mallen-Cooper 2006 and references therein), only recently have the impact of barriers and the need for construction of fishways begun to be assessed in Western Australia (e.g. Morgan \& Beatty 2006).

Five of the eight endemic fishes of south-western Australia inhabit the Margaret River, along with the Pouched Lamprey (Geotria australis, Grey 1851) and one exotic fish species (Morgan et al. 1998; Morgan \& Beatty 2003). It is one of the few rivers in the region (approximately $60 \mathrm{~km}$ long, catchment of $470 \mathrm{~km}^{2}$, mean annual discharge of $99800 \mathrm{ML}$ (1962-2004, Department of Water 2007)) that has had the main channel regulated by two weirs located approximately 15 -river $\mathrm{km}$ from its mouth. In order to mitigate the potential impact of these barriers, the first of two rock-ramp fishways (Fig. 1) was constructed in 2003 at the Apex Weir. The construction of the second fishway was completed in early 2006 to mitigate the impact on fish migration posed by a second weir (Barrett St) located only $\sim 1 \mathrm{~km}$ upstream of
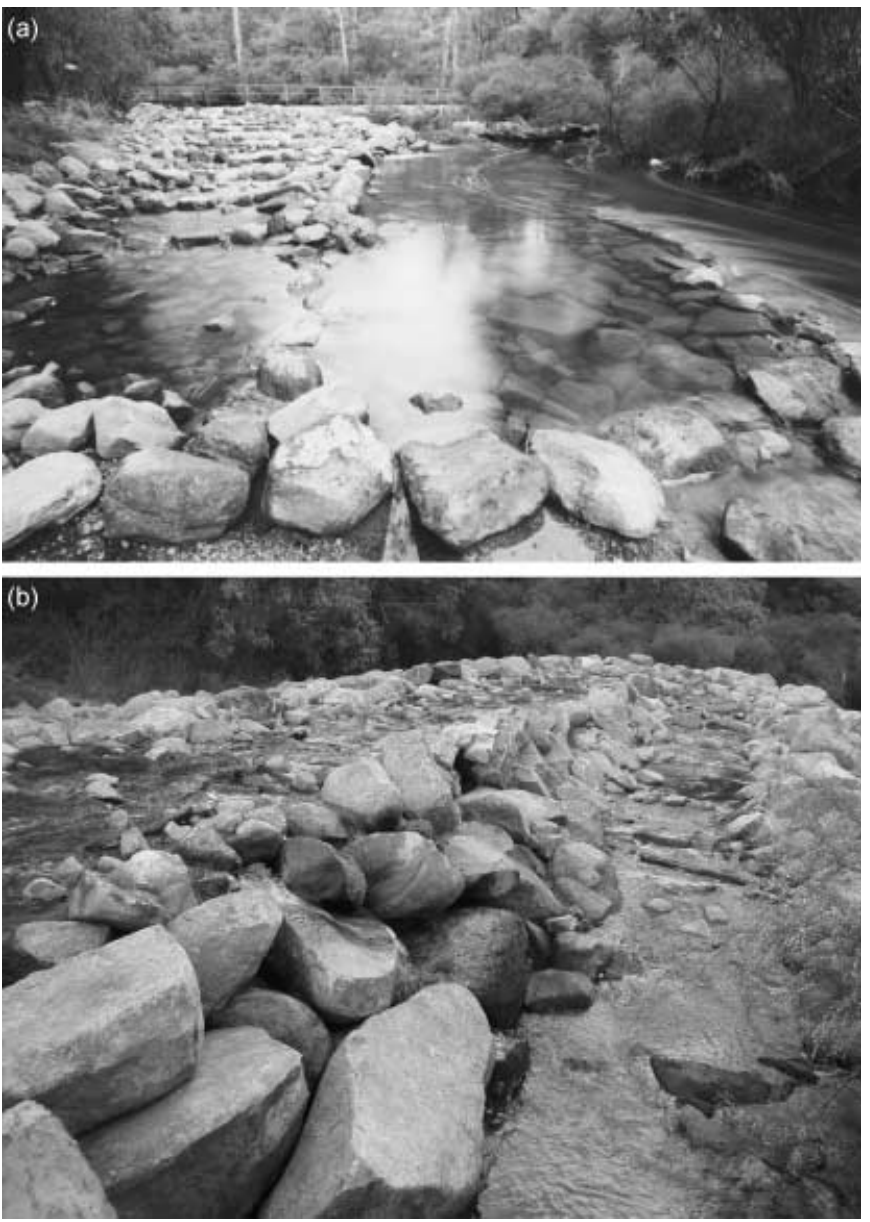

Figure 1. The Apex Weir Fishway (top) and the Barrett St Fishway (bottom) on the Margaret River, Western Australia. (Photo S. Visser).

the Apex Weir. Both fishways were constructed with a 1:20 gradient (see Morgan \& Beatty 2004 for other engineering aspects). The aim of this study was to determine the relative effectiveness of these fishways in restoring river connectedness by facilitating fish migrations.

\section{Methods}

Fishway monitoring occurred during July, August, September and November 2006; the major flow period of the river and the known migration period of endemic fishes within this region (e.g. Pen \& Potter 1991a). On each monitoring occasion, two fyke nets (2-mm woven mesh and 5-m wings) were set over three replicate 24-h periods at the upstream exit of both fishways (i.e. capturing fish that had negotiated the entire fishway); one facing upstream and one downstream to determine mean upstream and downstream fish movements. All fish captured were identified and the total length (TL) was measured to the nearest $1 \mathrm{~mm}$ before being promptly released at the site of capture. In order to further characterize the fish usage of the two fishways, the total number of fishes on each fishway was determined in 